\title{
Matrix Metalloproteinases and Temporomandibular Joint Disorder: A Review of the Literature
}

\author{
Logan Herm, Ardit Haxhia, Flavio de Alcantara Camejo, Lobat Tayebi and \\ Luis Eduardo Almeida *
}

Surgical Sciences Department, Oral Surgery, School of Dentistry, Marquette University, Milwaukee, WI 53233, USA; logan.herm@marquette.edu (L.H.); ardit.haxhia@marquette.edu (A.H.);

flavio.dealcantaracamejo@marquette.edu (F.d.A.C.); lobat.tayebi@marquette.edu (L.T.)

* Correspondence: luis.almeida@marquette.edu

Received: 30 September 2019; Accepted: 21 October 2019; Published: 24 October 2019

\begin{abstract}
Temporomandibular disorders (TMD) are progressive degenerative disorders that affect the components of the temporomandibular joint (TMJ), characterized by pain and limitations in function. Matrix metalloproteinases (MMP) are enzymes involved in physiological breakdown of tissue that can have a pathological effect from an increase in activity during inflammation. A PubMed search of the current literature (within the past 10 years) was conducted to identify human studies involving matrix metalloproteinases activity in TMJ components of patients with TMD. Two separate searches results in 34 studies, six of which met inclusion criteria. Immunohistochemistry and gene analysis were used to evaluate MMP expression in the study groups. This review showed the strongest evidence for involvement of MMP-1, MMP-2, and MMP-9 in TMD; however, limitations included low sample sizes and a lack of recent clinical studies. Future research with more definitive conclusions could allow for additional pharmaceutical targets in MMP when treating patients with temporomandibular disorders.
\end{abstract}

Keywords: matrix metalloproteinases; temporomandibular joint disorder; temporomandibular joint

\section{Introduction}

The temporomandibular joint (TMJ) is classified as a ginglymoarthrodial joint, allowing for rotational and translational movements in normal function. Its primary components include the glenoid fossa of the temporal bone, the articular disc, the head of the mandibular condyle, and masticatory muscles. This joint is capable of remodeling even after growth has stopped, allowing it to make structural changes and adapt to different physiological demands [1].

Temporomandibular disorders (TMD) are a group of degenerative disorders involving the components of the TMJ, which can lead to displacement of the disc, joint remodeling, and eventually osteoarthritis [2]. Disc displacement can occur anteriorly, posteriorly, medially, or laterally; however, it is most commonly displaced anteriorly [3]. TMD affects around $25 \%$ of the population, and it is characterized by orofacial pain, restricted range of motion, joint dysfunction, and ultimately, a decreased quality of life [2,4]. The etiology of TMD is still a topic of discussion; however, some known risk factors include trauma and microtrauma, malocclusion, and psychological factors, such as stress and anxiety [5].

The progression of TMD is classified primarily based on the location of the disc and its mobility during mandibular movement. In a normal functioning joint, the disc remains between the head of the mandibular condyle and the glenoid fossa through the full range of movement. In early stage TMD, the disc is displaced anteriorly when the mandible is closed and reduces to a normal location upon opening, classified as anterior disc displacement with reduction (ADDwR). In late stages of TMD, the disc is anteriorly displaced in both closed and open positions, classified as anterior disc 
displacement without reduction (ADDwoR). These later stages tend to be associated with more pain and limitation in mandibular mobility [2].

A more advanced staging guide to the internal derangements of TMD was created by Wilkes in 1989, placing patients into five categories based on clinical, radiographic (tomographic, arthrographic, and magnetic resonance imaging) and findings during surgery, including gross surface and anatomic changes to the disc and other components of the TMJ [6]. In the first stage, the early stage, patients present with clicking of the joint, but no pain, limited range of motion, or other symptoms. Radiographically and surgically, the disc is displaced slightly anteriorly, but all other aspects of the joint are normal. In Wilke's early/intermediate stage, the patient presents with additional symptoms, including episodes of pain, tenderness, and mechanical problems associated with the joint. Radiographically and surgically, the disc is displaced anteriorly, with slight deformation of its posterior aspect. In the intermediate stage there are more occurrences of pain, mechanical problems, including locking and decreased range of motion. In Wilke's intermediate/late stage of TMD, the patient has a chronic pain and decreased range of motion. Radiographically and surgically, an increased severity in comparison to the intermediate stage is noted, along with remodeling of the hard tissue surfaces of the joint. The disc, however, has yet to be perforated up to this stage. In the final stage, the late stage, patients present with crepitus and grinding in the joint with mandibular movement, chronic pain, restricted range of motion, and an overall decrease in function. Radiographically and surgically, the disc and hard tissues of the joint have undergone significant deformation, remodeling, and arthritic changes have occurred, including perforations of the attachments and erosion of articulating surfaces [6].

Matrix metalloproteinases (MMPs) are the major enzymes involved in extracellular matrix $(E C M)$ and basement membrane remodeling and degradation, along with other enzymes, such as a disintegrin and metalloproteinases (with or without thrombospondin), and plasminogen activators, among others [7-9]. These enzymes are seen in both physiological and pathological processes, including embryogenesis, apoptosis, bone remodeling, inflammation, arthritis, and cancer $[7,8]$. However, the role of MMPs is not limited to the ECM, as they have also been shown to play a role in regulating inflammatory response, namely by processing chemokines, growth factors, receptors, proteases, and other molecules and proteins [9]. They are a family of 26 endopeptidases that degrade collagen, gelatin, proteoglycans, and other ECM components, and they are regulated at the level of their gene expression (cytokines, growth factors, hormones, and others), posttranslational activation, and endogenous inhibition (tissue inhibitors of metalloproteinases [TIMP]) [8,10]. As inflammation occurs, however, processes involving these enzymes shift from physiological to pathological, and MMP activity results in excess tissue breakdown and damage [11].

Some MMPs have been suggested as being involved in angiogenesis, apoptosis, and osteoarthritis, processes which are seen in temporomandibular joint disorders [7]. Angiogenesis, found mostly in the synovial membrane in TMD, allows for new vessel formation to combat the hypoxia associated with an increase in the intra-articular pressure seen in TMD [12]. Chondrocytes undergo apoptosis in the early stages of TMD as the disc begins to remodel, and eventual cartilage degradation occurs, leading to osteoarthritic changes [4]. With evidence of the involvement of MMPs in these processes, and with the processes playing a crucial role in the progression of TMD, it would seem that MMP activity would be increased in joints of patients with the disorder. This paper aims to review the current scientific literature in order to investigate potential links between various MMPs and TMD.

\section{Methodology}

\subsection{Search Protocol}

Two independent electronic searches were conducted by two reviewers using PubMed to find relevant literature using Medical Subjective Headings (MeSH) Terms. The MeSH terms included in each search were: 
1. "Temporomandibular Joint Disorders/enzymology" (Mesh) OR "Temporomandibular Joint Disorders/metabolism" (Mesh) OR "Temporomandibular Joint Disorders/pathology" (Mesh)) AND "Humans" (Mesh)) AND "Immunohistochemistry" (Mesh)) AND "Matrix Metalloproteinases" (Mesh)

2. "Temporomandibular Joint Disorders" (MeSH Major Topic) AND "Matrix Metalloproteinases" [MeSH Major Topic]) AND “Humans" (MeSH Terms)

\subsection{Selection Protocol}

Inclusion and exclusion criteria were determined before the search results were evaluated.

Inclusion criteria used in selection included the following:

1. English language;

2. Living human subjects;

3. Publication within the past 10 years (since 2009);

4. Studies that evaluated samples of TMD and the level of MMP in the disease.

Exclusion criteria used in selection included the following:

1. Case studies;

2. Pilot studies;

3. Literature reviews.

\subsection{Data Analysis}

The data collected from each selected study, summarized in Table 1, included MMP type assessed in the study, sample size and groups, mean age involved in study, TMJ assessment, and the results of the study. Since the studies differed significantly in their methodology, a direct data analysis was unable to be conducted, and further evaluation of the quality of the included studies, such as statistical power, was not done beyond looking at the sample size.

Table 1. Studies that fit the inclusion criteria and published within the past 10 years [11,13-17]. Anterior disc displacement with reduction (ADDwR); anterior disc displacement without reduction (ADDwoR); matrix metalloproteinases (MMP); temporomandibular joint (TMJ).

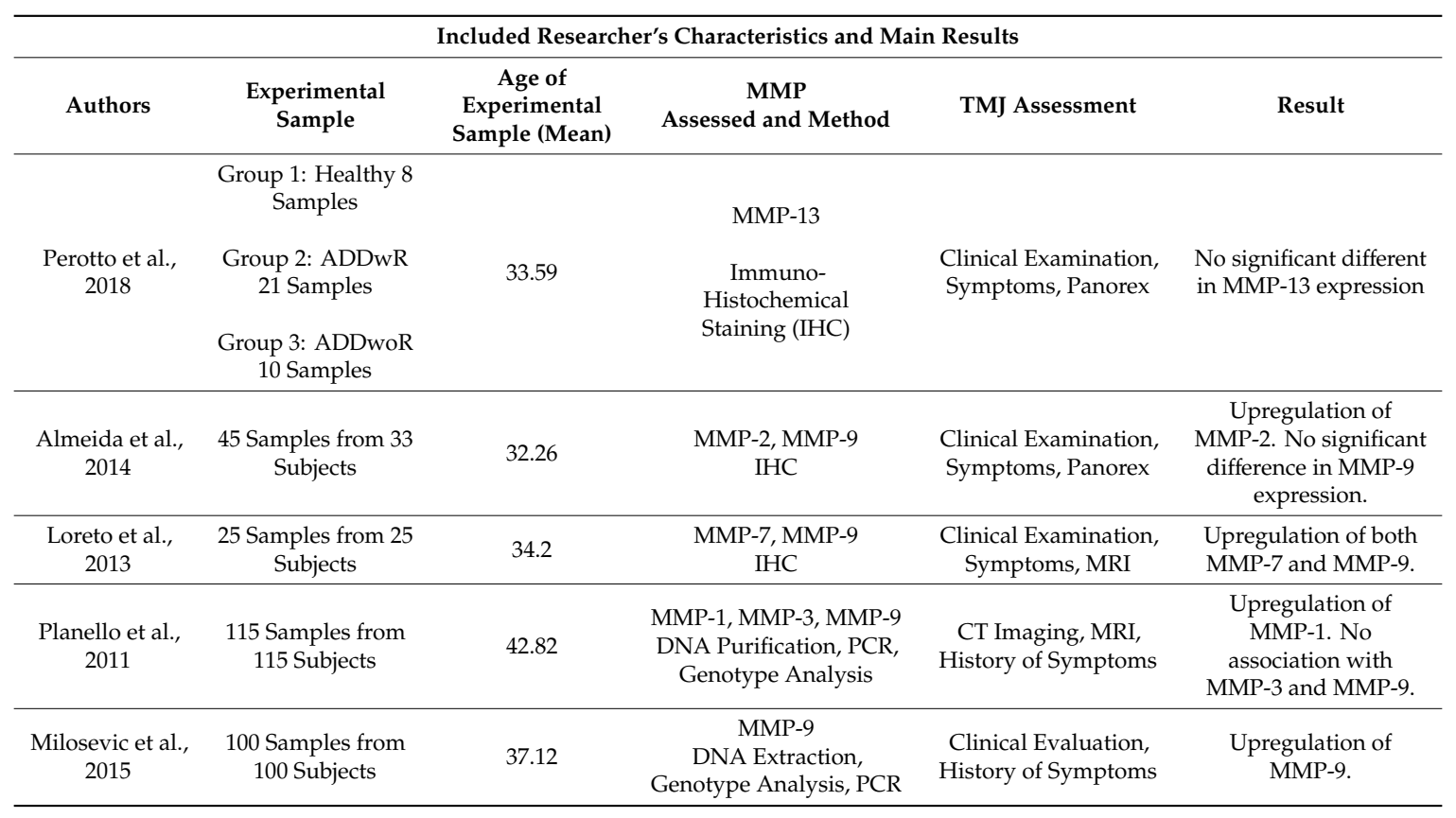


Table 1. Cont.

\begin{tabular}{|c|c|c|c|c|c|}
\hline \multicolumn{6}{|c|}{ Included Researcher's Characteristics and Main Results } \\
\hline Authors & $\begin{array}{l}\text { Experimental } \\
\text { Sample }\end{array}$ & $\begin{array}{c}\text { Age of } \\
\text { Experimental } \\
\text { Sample (Mean) }\end{array}$ & $\begin{array}{c}\text { MMP } \\
\text { Assessed and Method }\end{array}$ & TMJ Assessment & Result \\
\hline $\begin{array}{l}\text { Luo et al., } \\
\quad 2015\end{array}$ & $\begin{array}{c}\text { Group A: } 185 \\
\text { Healthy } \\
\text { Group B: } 141 \\
\text { ADDwR } \\
\text { Group C1: } 115 \\
\text { ADDwoR w/o OA } \\
\text { Group C2: } 206 \\
\text { ADDwoR w/ OA }\end{array}$ & $\begin{array}{l}\text { Group A: } 33.49 \\
\text { Group B: } 36.64 \\
\text { Group C: } 37.22\end{array}$ & $\begin{array}{c}\text { MMP-1 } \\
\text { DNA Sampling, } \\
\text { Genotype Analysis }\end{array}$ & $\begin{array}{l}\text { Clinical and } \\
\text { Radiographic } \\
\text { Examinations, } \\
\text { Symptoms }\end{array}$ & $\begin{array}{c}\text { Upregulation of } \\
\text { MMP-1 in ADDwoR } \\
\text { with or without TMJ } \\
\text { osteoarthritis. }\end{array}$ \\
\hline
\end{tabular}

\section{Results}

\subsection{General Outcomes}

Initial searches using the MeSH terms indicated above resulted in 34 studies, nine of which were duplicates and three of which were unable to be accessed. After removing duplicates and inaccessible studies, 22 studies remained. One study was not included due to samples being cadaveric, one focused on interleukins (IL) and used unspecified MMPs as markers for IL, two were animal studies, and two others were literature reviews. All other studies satisfied both the English language and the living human subject inclusion criteria, leaving 16 total studies. After including only studies published within the past 10 years, 6 studies remained, all of which were accepted based on all other indicated inclusion and exclusion criteria. Studies with researcher's characteristics and main results excluded from this review due to date of publication are included in Table 2 for additional comparison.

Table 2. Studies that fit all inclusion criteria, but were published more than 10 years ago [18-27].

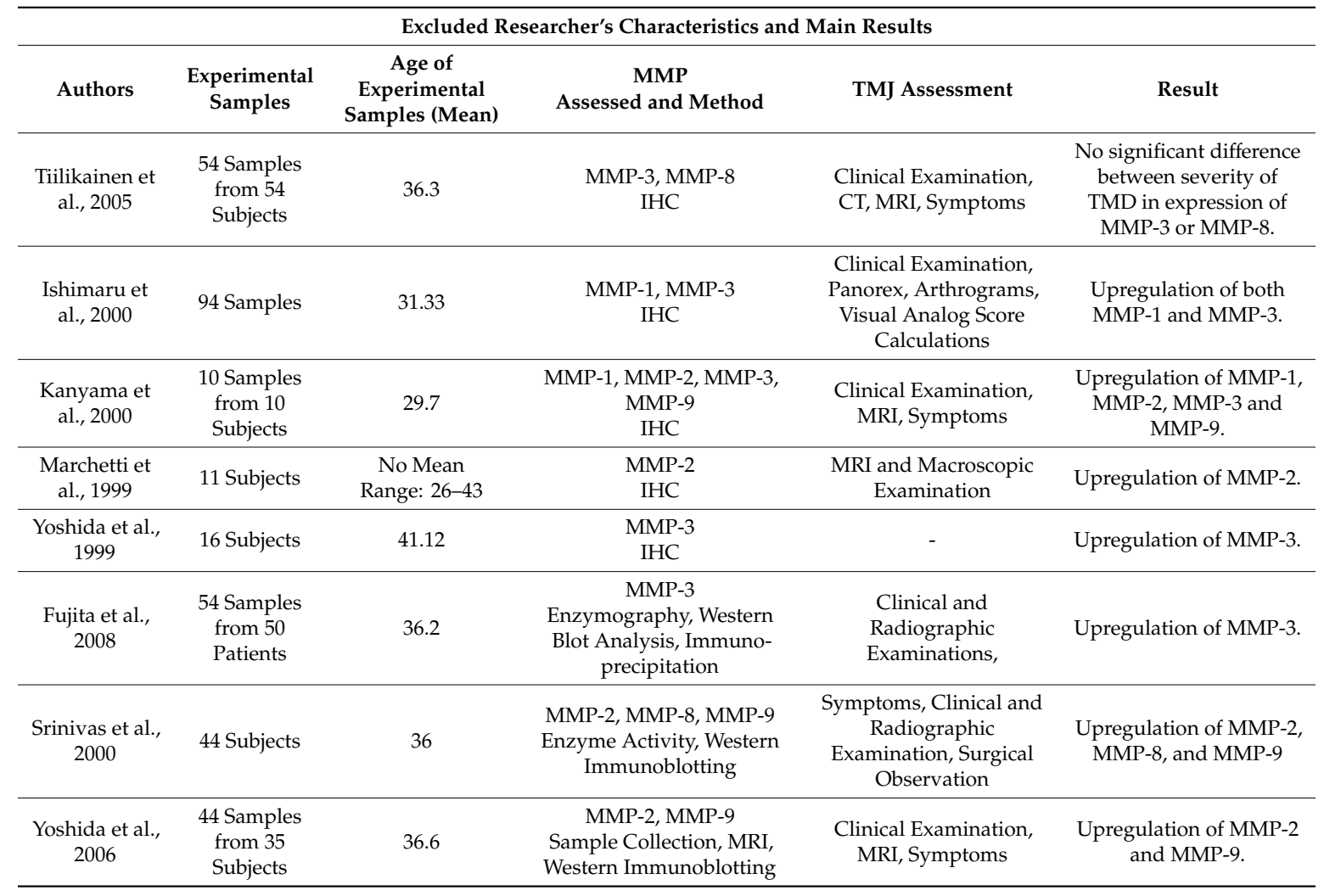


Table 2. Cont.

\begin{tabular}{cccccc}
\hline & \multicolumn{4}{c}{ Excluded Researcher's Characteristics and Main Results } \\
\hline Authors & $\begin{array}{c}\text { Experimental } \\
\text { Samples }\end{array}$ & $\begin{array}{c}\text { Age of } \\
\text { Experimental } \\
\text { Samples (Mean) }\end{array}$ & $\begin{array}{c}\text { MMP } \\
\text { Assessed and Method }\end{array}$ & TMJ Assessment & Result \\
\hline $\begin{array}{c}\text { Mizui et al., } \\
2001\end{array}$ & 86 Subjects & Range: 19-84 & $\begin{array}{c}\text { MMP-2 } \\
\text { Proteolytic Activity, } \\
\text { Enzymogram }\end{array}$ & Radiographic Analysis & Upregulation of MMP-2. \\
\hline $\begin{array}{c}\text { Tanaka et al., } \\
2001\end{array}$ & $\begin{array}{c}\text { 41 Samples } \\
\text { from 38 } \\
\text { Subjects }\end{array}$ & 34.8 & $\begin{array}{c}\text { MMP-2, MMP-9 } \\
\text { Enzyme Activity, Immuno- } \\
\text { blotting, Gelatinolytic } \\
\text { Activity }\end{array}$ & $\begin{array}{c}\text { Symptoms, Clinical and } \\
\text { Radiographic Exam }\end{array}$ & $\begin{array}{c}\text { MMP-2 and MMP-9 } \\
\text { in ADregulated more } \\
\text { in ADwoR than in } \\
\text { ADDwR. }\end{array}$ \\
\hline
\end{tabular}

\subsection{Description of Included Studies}

In 2018, Perotto et al. used 39 disc samples from 27 patients to look at MMP-13 expression in TMD. Exclusion criteria for subjects Perotto's study included use of orthodontic appliances, chronic anti-inflammatory use, history of diseases causing impaired immune function, such as HIV, diabetes, or any use of immunosuppressive therapy. The patients, with a mean age of 33.59, then filled out a pain questionnaire, had a clinical examination, and radiographs or CT imaging was performed for diagnostic purposes, placing patients into groupings of either ADDwR or ADDwoR. Surgery was performed on patients and samples were obtained and underwent immunohistological staining to analyze for MMP-13 activity. The researchers did not find a significant difference in expression of MMP-13 in samples from patients with TMD, in either the ADDwR or the ADDwoR groupings, when compared to the control group.

Almeida et al. (2014) analyzed activity of two matrix metalloproteinases and their protein levels in TMD, both MMP-2 and MMP-9. In this study, 45 disc samples from 33 patients (mean age of 32.36 years) were analyzed using immunohistological staining. Diagnosis was made using a pain questionnaire and clinical examination, grouping patients into ADDwR and ADDwoR, and selected patients were treated surgically following unsuccessful non-surgical treatment. Following immunohistochemical staining of samples obtained during surgery, MMP-2 was found to be significantly increased in samples from subjects with TMD when compared to the control. It was also found that there was an increase in MMP-2 in samples from patients with ADDwoR when compared to ADDwR, suggesting a correlation between progression of TMD and MMP-2 levels. Levels of MMP-9 showed no significant difference between the TMD disc samples when compared with control disc samples.

Loreto et al. (2013) used immunohistochemical staining to look at MMP-7 and MMP-9 in disc samples from subjects with TMD. They used 25 disc samples from 25 patients (mean age of 34), which were obtained surgically following unsuccessful non-surgical intervention after diagnosis using a history of present illness, clinical examination, and MRI. They assessed the severity of the disease by looking at unassisted maximum mouth opening and using a visual analog scale to assess pain. Following staining, both MMP-7 and MMP-9 were found to be expressed at levels significantly higher in samples from patients with TMD when compared to control samples.

Planello et al. (2011) analyzed the frequency of polymorphisms in genes coding for MMP-1, MMP-3, and MMP-9 proteinases in patients with TMJ degeneration. The study was conducted on 232 individuals, 115 of which had TMJ degeneration and a mean age of 42.82 . To diagnose the study group, the researchers used MRI and/or CT scans to image one or both mandibular condyles. Genomic DNA was gathered from epithelial buccal cells and a PCR reaction was performed for MMP-1, MMP-3, and MMP-9 coding genes. A genotype analysis using restriction fragment length polymorphisms was performed, and the frequency of each allele was determined in both groups. Compared to the control group, there was a statistically significant association between the MMP-1 genotype and the TMJ degeneration group. No association was found between the MMP-3 and MMP-9 genotypes and TMJ degeneration. 
Milosevic et al. (2015) studied polymorphisms of multiple genes in order to investigate their role in TMD. The study included 182 healthy individuals and 100 patients with TMD, with a mean age of 37.12. The TMD in the study group was assessed using clinical signs and symptoms. Genomic DNA was gathered from buccal swabs and genotyping was conducted in order to evaluate MMP-9 polymorphisms, as well as other enzyme polymorphisms outside the scope of this review. The researchers found a significant difference in genotype and allele frequency in the MMP-9 gene of TMD patients when compared to the control group.

Luo et al. (2015) studied polymorphisms of MMP-1 genes in healthy individuals and patients with articular disc derangement and TMJ osteoarthritis. The researchers split patients into three groups, as follows: Group A included 185 healthy individuals; Group B included 141 patients with unilateral ADDwR; and Group C included 321 patients with ADDwoR, 115 of which did not present TMJ osteoarthritis (C1) and 206 of which presented TMJ osteoarthritis (C2). These patients were diagnosed through clinical and radiographic examinations. Genomic DNA was extracted from buccal swabs and a PCR analysis was conducted in order to assess variations in the MMP-1 gene. Comparisons between the groups showed a variety of allele distributions. Groups A and B did not show a significant statistical difference. Groups A and $\mathrm{C}$ showed a noticeable statistical difference with an odds ratio of 2.455 after adjusting for age. When observing the subgroups in Group C, Group C1 had no difference with group B, while Group C2 had a significant statistical difference and an odds ratio of 1.912. Groups $\mathrm{C} 1$ and $\mathrm{C} 2$ showed no significant statistical difference. Overall, their findings suggest the MMP-1 gene is upregulated in patients with ADDwoR, and the presence of TMJ osteoarthritis had no influence.

\section{Discussion}

Differences in study design, groupings of samples, and MMPs analyzed prevented direct analysis of data in the present studies. Three studies, those of Perotto, Almeida, and Luo, not only grouped samples on the presence and absence of TMD, but also in the degree to which the disease had progressed, either ADDwR or ADDwoR. Many of the studies analyzed different MMPs, and there were different techniques used to test for expression of the MMP, including immunohistochemical staining and PCR. Four of the included studies, those of Almeida, Loreto, Planello, and Milosevic, analyzed the same MMP, MMP-9, and while Almeida and Planello found that there was no significant different in samples from subjects with TMD, Loreto and Milosevic found an increase in expression. The Kanyama study in 2000, the Srinivas study in 2000, the Yoshida study in 2006, and the Tanaka study in 2001, which were excluded due to date of publication, found that MMP-9 was upregulated in disc samples from subjects with TMD. The inconclusiveness as to whether or not there is a correlation between the levels of MMP-9 expression and TMD of some of the studies can likely be contributed to the small sample size in each.

Aside from MMP-9, the only other overlap of MMP in the included studies was MMP-1, which was found to be upregulated in TMD samples in both the study conducted by Planello, as well as the study conducted by Luo. Aside from these two MMPs, there is no additional overlap between MMPs analyzed in the included studies; however, there is some ability to compare with the studies excluded due to date of publication. MMP-2, which was found by Almeida to be upregulated in disc samples from subjects with TMD, was also found to have higher expression in TMD samples by Kanyama, Marchetti, Srinivas, Mizui, and Tanaka.

Based on the information present in the included studies, it is difficult to draw a definitive conclusion with respect to the involvement of most MMPs in TMD, even when the studies that were excluded due to date of publication are considered. The strongest evidence for MMP involvement in TMD lies with MMP-1, MMP-2, and MMP-9; however, there were limitations in all of the studies, the biggest being sample size, which ranged from only 25 to 141 samples in the included studies.

\section{Conclusions}

Despite the high prevalence of TMD in the population, current treatment modalities tend to have a poor long-term success and few patients seek treatment [2]. The available modalities are 
diverse, ranging from non-invasive techniques, such as physical therapy, ultrasound, low-level laser therapy, and splints, to minimally invasive techniques, such as corticosteroid injections, arthrocentesis of the joint, with or without platelet-rich plasma or hyaluronic acid injections, and arthroscopic surgery, to invasive procedures for the more advanced stage of TMD, which include discectomy, disc replacement, and the most invasive, total joint replacement $[2,28,29]$. It is recommended that attempts at treatment begin with non-invasive techniques and progress to invasive techniques, as risks with the invasive techniques involving open joint surgery can include facial nerve and optic lesions, transarticular and intracranial perforations, and pre-auricular hematoma, among others [3]. Further limitations and complications of arthroscopy, arthrocentesis, and orthognathic surgery used for treatment of TMD include arteriovenous fistula, pseudoaneurysm, infection, broken instruments in the joint, and condylar resorption [30,31]. Additionally, bruxism and dysfunctional oral habits have been shown to be risk factors for recurrent TMD symptoms after orthognathic surgery [32]. Due to limitations and complications of surgery, it is necessary to develop more efficacious techniques in non-invasive and pharmaceutical therapies for treating TMD.

Some of the pharmaceutical therapies for TMD include botox and cyclobenzaprine, which induce muscle relaxation, NSAIDs, and corticosteroids, which reduce pain and inflammation, and tricyclic antidepressants, which work to reduce pain [33]. However, these agents work to target the effects that TMD has on the patient rather than an underlying cause. To the researchers' knowledge, there are currently no pharmaceutical agents that are used to target an element of the underlying pathogenesis of TMD, such as MMPs, to stop the progression of this debilitating disorder.

There is ongoing pharmaceutical research to uncover potential MMP inhibitors for therapeutic use in different disease processes, such as cancer [34]. Thus far, however, limitations have prevented identification of a suitable therapeutic agent. The poorly understood specificity of their biological substrates makes it difficult to target specific MMPs, which causes detrimental problems, as MMPs are vital to survival [34]. There have been additional problems in its use, some of which include problems with oral bioavailability, toxicity, and metabolic stability [34,35]. Despite the unsuccessful attempts, knowledge of MMPs continues to evolve and the use of new and future technological advances, including use of CRISPR-Cas 9 and MMP-activatable optical probes, make the use of MMP as a pharmaceutical target more hopeful [34,35]. If and when a successful pharmaceutical agent is discovered targeting MMPs, having a good understanding of the specific MMPs involved in TMD progression could provide an expedited route to applying the therapy to TMD treatment.

More studies with larger sample sizes are needed to analyze the involvement of specific MMPs in TMD. With more concrete evidence of its role, and because of the nature of the enzymes, MMPs could prove to provide a better understanding of the progression of TMD and be a valuable pharmaceutical target for therapy.

Author Contributions: Conceptualization, F.d.A.C. and L.E.A.; Methodology, L.H., A.H.; Software, Not applicable; Validation, L.E.A., L.H., and A.H.; Formal Analysis, Not applicable; Investigation, L.H., A.H. and F.d.A.C.; Resources, L.H., A.H.; Data Curation, L.H., A.H.; Writing-Original Draft Preparation, L.H., A.H.; Writing-Review \& Editing, L.E.A., L.H., A.H., F.d.A.C. and L.T.; Visualization, L.E.A.; Supervision, F.d.A.C., L.T. and L.E.A.; Project Administration, L.E.A.; Funding Acquisition, Not applicable.

Funding: This research received no external funding.

Acknowledgments: There are no acknowledgements and no funding was used for this review.

Conflicts of Interest: No conflicts of interest.

\section{References}

1. Mathew, A.L.; Sholapurkar, A.A.; Pai, K.M. Condylar Changes and Its Association with Age, TMD, and Dentition Status: A Cross-Sectional Study. Int. J. Dent. 2011, 2011, 1-7. [CrossRef] [PubMed]

2. Murphy, M.K.; MacBarb, R.F.; Wong, M.E.; Athanasiou, K.A. Temporomandibular Joint Disorders: A Review of Etiology, Clinical Management, and Tissue Engineering Strategies. Int. J. Oral Maxillofac. Implant. 2013, 28, e393-e414. [CrossRef] [PubMed] 
3. Poluha, R.L.; Canales, G.D.L.T.; Costa, Y.M.; Grossmann, E.; Bonjardim, L.R.; Conti, P.C.R. Temporomandibular joint disc displacement with reduction: A review of mechanisms and clinical presentation. J. Appl. Oral Sci. 2019, 27, 1-9. [CrossRef] [PubMed]

4. Wang, X.; Zhang, J.; Gan, Y.; Zhou, Y. Current Understanding of Pathogenesis and Treatment of TMJ Osteoarthritis. J. Dent. Res. 2015, 94, 666-673. [CrossRef]

5. Sójka, A.; Stelcer, B.; Roy, M.; Mojs, E.; Pryliński, M. Is there a relationship between psychological factors and TMD? Brain Behav. 2019, 9, 1-11. [CrossRef]

6. Wilkes, C.H. Internal Derangements of the Temporomandibular Joint: Pathological Variations. Arch. Otolaryngol. Head Neck Surg. 1989, 115, 469-477. [CrossRef]

7. Amălinei, C.; Căruntu, I.D.; Giuşcă, S.E.; Bălan, R.A. Matrix metalloproteinases involvement in pathologic conditions. Rom. J. Morphol. Embryol. Rev. Roum. Morphol. Embryol. 2010, 51, 215-228.

8. Peng, W.-J.; Yan, J.-W.; Wan, Y.-N.; Wang, B.-X.; Tao, J.-H.; Yang, G.-J.; Pan, H.-F.; Wang, J. Matrix Metalloproteinases: A Review of Their Structure and Role in Systemic Sclerosis. J. Clin. Immunol. 2012, 32, 1409-1414. [CrossRef]

9. Butler, G.; Overall, C. Matrix metalloproteinase processing of signaling molecules to regulate inflammation. Periodontology 2000, 63, 123-148. [CrossRef]

10. Verma, R.P.; Hansch, C. Matrix metalloproteinases (MMPs): Chemical-biological functions and (Q)SARs. Bioorg. Med. Chem. 2007, 15, 2223-2268. [CrossRef]

11. Almeida, L.E.; Caporal, K.; Ambros, V.; Azevedo, M.; Noronha, L.; Leonardi, R.; Trevilatto, P.C. Immunohistochemical expression of matrix metalloprotease-2 and matrix metalloprotease- 9 in the disks of patients with temporomandibular joint dysfunction. J. Oral Pathol. Med. 2014, 44, 75-79. [CrossRef] [PubMed]

12. Ke, J.; Liu, Y.; Long, X.; Li, J.; Fang, W.; Meng, Q.; Zhang, Y. Up-regulation of vascular endothelial growth factor in synovial fibroblasts from human temporomandibular joint by hypoxia. J. Oral Pathol. Med. 2007, 36, 290-296. [CrossRef] [PubMed]

13. Perotto, J.H.; Camejo, F.D.A.; Doetzer, A.D.; Almeida, L.E.; Azevedo, M.; Olandoski, M.; Noronha, L.; Trevilatto, P.C. Expression of MMP-13 in human temporomandibular joint disc derangement and osteoarthritis. Cranio 2017, 36, 161-166. [CrossRef] [PubMed]

14. Loreto, C.; Leonardi, R.; Musumeci, G.; Pannone, G.; Castorina, S. An Ex Vivo Study on Immunohistochemical Localization of MMP-7 and MMP-9 in Temporomandibular Joint Discs with Internal Derangement. Eur. J. Histochem. 2013, 57, e12. [CrossRef] [PubMed]

15. Planello, A.C.; Campos, M.I.G.; Meloto, C.B.; Secolin, R.; Rizatti-Barbosa, C.M.; Line, S.R.P.; De Souza, A.P.; Rizatti-Barbosa, C.M. Association of matrix metalloproteinase gene polymorphism with temporomandibular joint degeneration. Eur. J. Oral Sci. 2011, 119, 1-6. [CrossRef]

16. Milosevic, N.; Nikolic, N.; Djordjevic, I.; Todorović, A.; Lazić, V.; Milašin, J. Association of Functional Polymorphisms in Matrix Metalloproteinase-9 and Glutathione S-Transferase T1 Genes with Temporomandibular Disorders. J. Oral Facial Pain Headache 2015, 29, 279-285. [CrossRef]

17. Luo, S.; Deng, M.; Long, X.; Li, J.; Xu, L.; Fang, W. Association between polymorphism of MMP-1 promoter and the susceptibility to anterior disc displacement and temporomandibular joint osteoarthritis. Arch. Oral Boil. 2015, 60, 1675-1680. [CrossRef]

18. Tiilikainen, P.; Pirttiniemi, P.; Kainulainen, T.; Pernu, H.; Raustia, A. MMP-3 and -8 expression is found in the condylar surface of temporomandibular joints with internal derangement. J. Oral Pathol. Med. 2005, 34, 39-45. [CrossRef]

19. Ishimaru, J.-I.; Oguma, Y.; Goss, A. Matrix metalloproteinase and tissue inhibitor of metalloproteinase in serum and lavage synovial fluid of patients with temporomandibular joint disorders. Br. J. Oral Maxillofac. Surg. 2000, 38, 354-359. [CrossRef]

20. Kanyama, M.; Kuboki, T.; Kojima, S.; Fujisawa, T.; Hattori, T.; Takigawa, M.; Yamashita, A. Matrix metalloproteinases and tissue inhibitors of metalloproteinases in synovial fluids of patients with temporomandibular joint osteoarthritis. J. Orofac. Pain 2000, 14, 20-30.

21. Marchetti, C.; Cornaglia, I.; Casasco, A.; Bernasconi, G.; Baciliero, U.; Stetler-Stevenson, W. Immunolocalization of gelatinase-A (matrix metalloproteinase-2) in damaged human temporomandibular joint discs. Arch. Oral Boil. 1999, 44, 297-304. [CrossRef] 
22. Yoshida, H.; Yoshida, T.; Iizuka, T.; Sakakura, T.; Fujita, S. The localization of matrix metalloproteinase-3 and tenascin in synovial membrane of the temporomandibular joint with internal derangement. Oral Dis. 1999, 5, 50-54. [CrossRef] [PubMed]

23. Fujita, H.; Morisugi, T.; Tanaka, Y.; Kawakami, T.; Kirita, T.; Yoshimura, Y. MMP-3 activation is a hallmark indicating an early change in TMJ disorders, and is related to nitration. Int. J. Oral Maxillofac. Surg. 2009, 38, 70-78. [CrossRef] [PubMed]

24. Srinivas, R.; Sorsa, T.; Tjäderhane, L.; Niemi, E.; Raustia, A.; Pernu, H.; Teronen, O.; Salo, T. Matrix metalloproteinases in mild and severe temporomandibular joint internal derangement synovial fluid. Oral Surg. Oral Med. Oral Pathol. Oral Radiol. Endodontol. 2001, 91, 517-525. [CrossRef] [PubMed]

25. Yoshida, K.; Takatsuka, S.; Hatada, E.; Nakamura, H.; Tanaka, A.; Ueki, K.; Nakagawa, K.; Okada, Y.; Yamamoto, E.; Fukuda, R. Expression of matrix metalloproteinases and aggrecanase in the synovial fluids of patients with symptomatic temporomandibular disorders. Oral Surg. Oral Med. Oral Pathol. Oral Radiol. Endodontol. 2006, 102, 22-27. [CrossRef]

26. Mizui, T.; Ishimaru, J.-I.; Miyamoto, K.; Kurita, K. Matrix metalloproteinase-2 in synovial lavage fluid of patients with disorders of the temporomandibular joint. Br. J. Oral Maxillofac. Surg. 2001, 39, 310-314. [CrossRef]

27. Tanaka, A.; Kumagai, S.; Kawashiri, S.; Takatsuka, S.; Nakagawa, K.; Yamamoto, E.; Matsumoto, N. Expression of matrix metalloproteinase-2 and -9 in synovial fluid of the temporomandibular joint accompanied by anterior disc displacement. J. Oral Pathol. Med. 2001, 30, 59-64. [CrossRef]

28. Fernandes, G.; Gonçalves, D.; Conti, P. Musculoskeletal Disorders. Dent. Clin. N. Am. 2018, 62, 553-564. [CrossRef]

29. Zotti, F.; Albanese, M.; Rodella, L.F.; Nocini, P.F. Platelet-Rich Plasma in treatment of Temporomandibular Joint: Narrative Review. Int. J. Mol. Sci. 2019, 20, 277. [CrossRef]

30. Catherine, Z.; Breton, P.; Bouletreau, P. Condylar resorption after orthognathic surgery: A systematic review. Rev. Stomatol. Chir. Maxillo Faciale Chir. Orale 2016, 117, 3-10. [CrossRef]

31. Laskin, D.M. Arthroscopy versus Arthrocentesis for Treating Internal Derangements of the Temporomandibular Joint. Oral Maxillofac. Surg. Clin. N. Am. 2018, 30, 325-328. [CrossRef] [PubMed]

32. Bruguiere, F.; Sciote, J.J.; Roland-Billecart, T.; Raoul, G.; Machuron, F.; Ferri, J.; Nicot, R. Pre-operative parafunctional or dysfunctional oral habits are associated with the temporomandibular disorders after orthognathic surgery: An observational cohort study. J. Oral Rehabil. 2018, 46, 321-329. [CrossRef] [PubMed]

33. Ouanounou, A.; Goldberg, M.; Haas, D.A. Pharmacotherapy in Temporomandibular Disorders: A Review. J. Can. Dent. Assoc. 2017, 83, 1-8.

34. Vandenbroucke, R.E.; Libert, C. Is there new hope for therapeutic matrix metalloproteinase inhibition? Nat. Rev. Drug Discov. 2014, 13, 904-927. [CrossRef]

35. Winer, A.; Adams, S.; Mignatti, P. Matrix Metalloproteinase Inhibitors in Cancer Therapy: Turning Past Failures into Future Successes. Mol. Cancer Ther. 2018, 17, 1147-1155. [CrossRef]

(C) 2019 by the authors. Licensee MDPI, Basel, Switzerland. This article is an open access article distributed under the terms and conditions of the Creative Commons Attribution (CC BY) license (http://creativecommons.org/licenses/by/4.0/). 